\title{
UTILIZAÇÃO DO PERFIL DOS ESTUDANTES COMO PARÂMETRO DA GESTÃO EDUCACIONAL
}

\author{
http://dx.doi/10.5902/2318133825913
}

\author{
Decio Tadeu Dalcin Pigato \\ Instituto Federal de Educação, Ciência e Tecnologia do Rio Grande do Sul, Brasil.
}

\author{
Silvana Maria Paes Cangiani \\ Instituto Brasileiro de Geografia e Estatística, Brasil.
}

\begin{abstract}
Resumo
No presente trabalho buscou-se compreender como o diagnóstico da realidade dos estudantes do ensino fundamental é conduzida no âmbito da rede municipal de educação de Viamão/RS. A partir desta compreensão buscou-se elaborar uma metodologia para a utilização do perfil dos estudantes como parâmetro de gestão. Para tanto, estruturou-se a pesquisa no diagnóstico da realidade dos estudantes e nas contribuições oferecidas pelo banco de dados da Pesquisa Nacional de Saúde do Escolar - Pense - do IBGE. O trabalho gerou um produto para a rede municipal de ensino, o qual possibilita a ampliação do cadastro dos alunos, com a proposta de inclusão de parâmetros que contemplam variáveis as quais permitem identificar melhor a diversidade presente nas escolas.

Palavras-chave: perfil dos estudantes, diagnóstico, gestão educacional, ensino fundamental.
\end{abstract}

\section{USING THE PROFILE OF STUDENTS AS A PARAMETER OF EDUCATIONAL MANAGEMENT}

\begin{abstract}
This study is an attempt to understand the reality of the education network in the city of Viamão, in the state of Rio Grande do Sul, in performing the diagnosis of students' profiles. The aim of this research is to formulate a methodology for the use of the students' profiles as a management parameter. In order to do that, the research was structured in the diagnosis of the reality of students and in the contributions offered by an important database. The study has led to one outcome's for the educational network that allows widening of the students' records with the formulation of a parameter including variables that are more suitable to the diversity seen in the schools.

Key-words: student profile, diagnosis, educational management, elementary school.
\end{abstract}




\section{Introdução}

- studar a relação existente entre o aluno, a sua família e o ambiente escolar na sociedade contemporânea, em constante mutação, possibilita ao gestor - escolar entender a complexidade que chega à sala de aula. Além disso, permite ao educador compreender e conduzir diferentes situações que envolvem o processo de ensino e de aprendizagem.

É comum, entre os especialistas da educação, a afirmação de que a escola e a família compartilha108m funções sociais, políticas e educacionais, uma vez que contribuem e influenciam na formação do cidadão: a família como agente socializante, como rede de apoio e desenvolvimento humano, e a escola como um contexto diversificado de desenvolvimento e aprendizado, um local de diversidade cultural, atividades, regras e valores (Polonia; Dessen, 2005; Ramires, 2004).

No século 21 a rapidez com que as transformações históricas ocorrerem tornou a escola mais complexa, com o surgimento de novos valores na sociedade contemporânea. Houve modificações no entendimento de classe, gênero, sexualidade, etnia, raça e nacionalidade, bem como cada indivíduo e cada grupo social desenvolveram mecanismos próprios para a compreensão desses valores, procurando posicionarem-se em relação a si próprios e ao mundo (Fávero, 2010).

É de fundamental importância para o educador conhecer o aluno, pois esse conhecimento é central nos processos de ensino e de aprendizagem, no entanto, essa não é uma tarefa fácil. Um planejamento educacional mais abrangente precisa considerar as necessidades individuais de cada aluno, de forma a potencializar o seu desenvolvimento.

Para a Organização para a Educação, a Ciência e a Cultura das Nações Unidas (Unesco, 2002), a educação precisa permitir aos alunos o seu desenvolvimento como pessoas, favorecendo sua atuação na sociedade. Porém, alerta que ainda persiste uma cultura que não considera os alunos como sujeitos ativos na construção do conhecimento, mas meros receptores e reprodutores desse conhecimento. É urgente conhecer com profundidade o que o aluno pensa da escola, o que espera dela, quais suas aspirações e valores, e, posteriormente, considerar essas informações nos sistemas educativos.

Nessa linha de pensamento, esta pesquisa fundamentou-se na relação existente entre o perfil do aluno e o ambiente escolar, com vistas a entender melhor a diversidade em sala de aula e possibilitar uma melhor compreensão das múltiplas situações que envolvem o processo de ensino e aprendizagem.

\section{A constituição do problema e dos objetivos de pesquisa}

Estruturou-se o problema de pesquisa deste estudo a partir da realidade existente na rede municipal de ensino situada no município de Viamão, Estado do Rio Grande do Sul.

Buscou-se compreender, por meio de visitas à Secretaria Municipal de Educação de Viamão, de que forma se realiza o diagnóstico da realidade dos estudantes do ensino fundamental, que tipo de documento é utilizado, qual a periodicidade do levantamento e que ações são desencadeadas a partir desse levantamento do perfil do aluno; analisar um banco de dados público, a Pesquisa Nacional de Saúde do Escolar - Pense -, realizada em 2012 pelo Instituto Brasileiro de Geografia e Estatística (IBGE, 2012), a fim de 
quantificar e identificar as variáveis relevantes, procurando entender as principais tendências apontadas pela pesquisa e as possibilidades de utilização dessas variáveis como instrumento de gestão; propor ao município de Viamão uma metodologia que utiliza o perfil de estudante do ensino fundamental como parâmetro de gestão educacional, que possibilite uma melhor compreensão da diversidade em sala de aula estruturada em três pilares: como o município faz hoje, o que a Pense (IBGE, 2012) apresentou de importante e o que a literatura recomenda.

\section{Procedimentos metodológicos}

A pesquisa foi desenvolvida em quatro etapas sequenciais, estruturadas como se descreve a seguir.

Primeira etapa: consistiu numa pesquisa bibliográfica a partir da qual se procurou analisar a constituição de um aluno ideal preconizada na história da educação moderna, que visa à homogeneidade sem espaço para a diferença; a importância do reconhecimento da diferença e da realidade local para compreender quem são os estudantes e em que comunidades estão inseridos; a importância desse reconhecimento na ação docente.

Segunda etapa: visitou-se a Secretaria Municipal de Educação de Viamão para compreender de que forma se realiza o levantamento do perfil dos estudantes do ensino fundamental, que tipo de documento é utilizado, qual a periodicidade do levantamento e que ações são desencadeadas a partir do levantamento. Foram realizadas entrevistas semiestruturadas com os responsáveis, bem como coleta de documentos diversos.

Terceira etapa: realizou-se um estudo das variáveis da Pense (IBGE, 2012), com o intuito de verificar suas contribuições na elaboração de uma metodologia de diagnóstico de realidade dos estudantes do ensino fundamental. O banco de dados da Pense (IBGE, 2012) foi selecionado por tratar-se de metodologia de análise de perfil do escolar no ambiente educacional referendada internacionalmente, com amostragem estatisticamente representativa, realizada com alunos do $9^{\circ}$ ano do ensino fundamental.

A seleção, quantificação e análise das variáveis pesquisadas pela Pense (IBGE, 2012) objetivam quantificar e identificar quais as variáveis que apresentam potencial para a elaboração de uma metodologia de diagnóstico de perfil de estudantes do ensino fundamental.

Foram selecionadas as variáveis relacionadas ao tema da pesquisa, com um recorte no enfoque educacional para perfil do aluno: raça, cor, sexo, idade, trabalho; contexto familiar: número de residentes no domicílio do aluno, bens e serviços na residência do aluno, se o aluno mora com o pai ou com a mãe; ambiente educacional em casa: escolaridade materna e paterna, se os pais sabem o que o aluno faz no tempo livre, se o aluno falta à aula sem autorização dos pais ou responsáveis, se os pais ou responsáveis verificaram seus deveres de casa, se os pais ou responsáveis entenderam seus problemas e preocupações; ambiente educacional na escola: violência e segurança entre alunos na escola. 
Quarta etapa. a partir da análise da bibliografia, dos dados coletados no âmbito do município e do estudo da Pense (IBGE, 2012), foi proposta ao município de Viamão uma metodologia de diagnóstico do perfil de estudante do ensino fundamental fundamentada em três pilares: como o município faz hoje, o que a Pense (IBGE, 2012) apresentou de importante e o que a literatura recomenda.

\section{A escola moderna e a constituição do aluno ideal}

Propor a caracterização do perfil do aluno como parâmetro de gestão passa pela compreensão dos diferentes aspectos associados a esse aluno, entre eles a constituição da escola moderna, marcada pela homogeneização e pela produção de um modelo de aluno ideal com marcadores bem definidos em termos de raça, etnia, classe social e gênero.

Xavier (2003, p. 57) que argumenta que "a escola, na sua configuração atual, é uma instituição social típica da Modernidade. Atualmente, os conceitos educação e escolarização são vistos como sinônimos, mas nem sempre foi assim. Ela aponta que se "recuarmos no tempo, veremos, porém, que a história da educação não se confunde com a história da escola" (p. 57).

Uma breve visão histórica sobre a educação mostra que, nas origens da humanidade, o homem se educava a partir da observação e compreensão do ambiente natural, bem como interagindo com outros seres humanos. Os conhecimentos desenvolvidos pela própria experiência eram transmitidos para as novas gerações, educadas e treinadas para a vida (Xavier, 2003).

Para Saviani (1991 apud Xavier, 2003), a origem da escola parece situar-se no período em que o homem deixou de ser predominantemente coletor e se fixou na terra, passando a exercer a agricultura. Durante a Idade Média, não houve alteração nessa situação, isto é, os proprietários de terras tinham condições de frequentar a escola, enquanto isso, os trabalhadores ocupavam-se com a lida da terra e dos animais, educavam-se trabalhando no próprio processo laboral (Xavier, 2003).

Já no século 13 os colégios podiam ser considerados asilos para alunos pobres, onde não se ensinava. Esses asilos tinham a função de abrigar os estudantes, que viviam em comunidade e submetidos às regras monásticas. Somente a partir do século 15 essas comunidades tornaram-se instituições de ensino, sob rígida hierarquia, dando início ao ensino das artes. Essas instituições são consideradas os modelos que originaram as instituições escolares do século 15 ao 17 (Ariès, 1981). A partir do século 18 as transformações ocorridas na sociedade, decorrentes da Revolução Francesa e do início da era industrial, possibilitaram o acesso à escola para as classes mais populares (Xavier, 2003).

Para entender melhor como essas transformações influenciaram o processo de escolarização, Varela e Alvarez-Uria (1991) destacaram que a consolidação da institucionalização da escola obrigatória aconteceu a partir da metade do século 19 e princípio do século 20 , quando foram tomadas medidas sociais que atingiram as classes trabalhadoras, tais como, construções de casas para as classes operárias, regulamentação do trabalho de mulheres e crianças, criação de escolas dominicais e de adultos. $\mathrm{O}$ alvo dos governos é o menino trabalhador, porém, sua educação visa a mantê-lo servil, longe dos saberes que possam resultar em sua integração em posições de comando.

\begin{tabular}{|l|l|l|l|l}
\hline Regae: Rev. Gest. Aval. Educ. & Santa Maria & v. 6 & n. 12 & Maio/ago., 2017
\end{tabular} p. $107-123$ 
Para Ariès (1981, p.166), "a preocupação com a idade se tornaria fundamental no século XIX e em nossos dias". Segundo Ariès (1981), a escola evoluiu junto ao entendimento das fases da vida da criança. No início, era comum a mistura das idades. Alunos com diferentes idades conviviam nas escolas durante a Idade Média, vivendo sob um espírito de liberdade de costumes.

Ao longo do século 19 ocorreram inúmeras discussões sobre a escola obrigatória para todos e, a partir do século 20, a sociedade passou por mudanças drásticas, em consequência a escola também passa por transformações. Para melhor compreender os eventos relevantes nesse período destaca-se o estudo conduzido por Chaves (2015) sobre as relações entre a escola e o aluno. A autora diz que no último século a escola pode ser caracterizada pelo seu processo de socialização, bem como pelo declínio em seu programa institucional. Diante dessa constatação propõe uma investigação que pressupõe a construção da identidade do estudante a partir de relações complexas entre os diferentes sujeitos que compõem a escola.

Do ponto de vista histórico, Chaves (2015) relatou que, no Brasil, a escola como conhecemos tomou forma somente em meados do século 19, quando foram construídas instalações apropriadas para abrigar as estruturas escolares. Durante parte do século 20 os governos administram o sistema escolar de modo a inibir a diversidade, com ênfase na homogeneização. No entanto, apesar da ênfase no homogêneo, esse projeto apresenta inúmeras variações em função das condições geopolíticas, culturais e econômicas das localidades. As contradições entre a homogeneização desejada pelos governos e as diversidades encontradas podem ser a origem de alguns problemas atuais da escola, com destaque para a incoerência existente entre os princípios de homogeneidade e as diferenças individuais dos alunos (Chaves, 2015).

A sociedade contemporânea apresenta-se mais heterogênea, com novas perspectivas para o entendimento da formação do aluno. Esse aluno passou a ser influenciado também pelas próprias experiências, de modo que o aluno disciplinado cede lugar a um sujeito mais participativo, demandando uma individualização que antes não existia (Chaves, 2015).

Diante dessa nova realidade, Chaves (2015) alertou para o caráter homogeneizante do projeto escolar e indica que "novas formas de socialização precisam ser reinventadas na medida em que alunos ainda são pouco compreendidos e aceitos por quem ensina, dirige e comanda a escola" (p. 1157). O aluno ideal é substituído pelo aluno real, heterogêneo, sob novas influências culturais e sociais.

Aspectos históricos produziram uma escola homogênea, com pouco espaço para novas culturas, moldando os alunos aos interesses da época vigente. Esse ideal de aluno, historicamente constituído, ainda está presente na educação, no entanto, a sociedade mudou drasticamente, o que nos leva a refletir sobre a interpretação do termo aluno ideal e suas consequências para a educação.

As questões envolvendo o aluno ideal têm relevância na educação, pois trazem dentro de si as dificuldades em torno da aprendizagem dos alunos que não atendem à expectativa desejada. Essa expectativa em relação aos alunos foi explorada na pesquisa desenvolvida por Santos, Cruz e Belém (2014). Os autores estudaram as representações 
sociais de adolescência e de aluno ideal e observaram que os professores, quando se referem ao aluno ideal, usam termos como intelectual, comportamento adequado e relações sociais. Parece claro que, em termos de importância, o comportamento adequado se sobrepõe à aprendizagem.

A expectativa e a percepção que os professores constroem em relação aos alunos são um tema que intriga os pesquisadores, que buscam compreender essa temática por meio de diferentes metodologias. Salienta-se a pesquisa realizada por Lopes (2008), que analisou 371 encaminhamentos de alunos aos serviços de apoio por apresentarem dificuldades de aprendizagem, segundo a visão dos seus professores, considerando 105 entrevistas com professores sobre a percepção que tinham desses alunos e suas relações com a inclusão escolar. Os resultados mostraram que em $70 \%$ dos pareceres analisados, as questões comportamentais e disciplinares são consideradas as causas da aprendizagem deficiente.

A heterogeneidade presente em sala de aula, somada à expectativa em relação ao aluno ideal, à percepção dos professores em relação a esses alunos e ao desconhecimento dos fatores relacionados com as dificuldades de aprendizagem, torna necessário refletir e propor ações que busquem mitigar as dificuldades resultantes desse processo.

\section{As contribuições dos debates sobre a área da educação no Brasil}

No século 21 os planos e projetos relacionados à educação brasileira passaram a receber influência dos debates e desdobramentos decorrentes da realização das Conferências Nacionais de Educação - Conae - realizadas em 2010 e 2014 e dos Planos Nacional, Estaduais e Municipais de Educação. Novos temas entram no debate, tais como: diversidade, justiça social, inclusão e direitos humanos, evidenciando a resistência social, política e eclesial ao reconhecimento efetivo da realidade escolar e estudantil com que a educação se depara na Contemporaneidade.

As questões relativas com justiça social, igualdade, diversidade e inclusão são parte do desenvolvimento da própria educação brasileira, porém, nem sempre foram reconhecidas pelo poder público como merecedoras de políticas. Somente em 2010 é que foram inseridas na agenda social e política, na mídia, na esfera jurídica e na política educacional (Conae, 2010). A II Conferência Nacional da Educação (Conae, 2014) produziu um documento final intitulado $O$ plano nacional de educação na articulação do sistema nacional de educação: participação popular, cooperação federativa e regime de colaboração (Conae, 2014).

O atual Plano Nacional de Educação (Brasil, 2014) apresentou como objetivos e diretrizes a erradicação do analfabetismo, universalização do atendimento escolar, superação das desigualdades educacionais, melhoria da qualidade de ensino, formação para o trabalho, promoção da sustentabilidade socioambiental, promoção humanística, científica e tecnológica do país, estabelecimento de meta de aplicação de recursos em educação como proporção do produto interno bruto, valorização dos profissionais da educação e difusão dos princípios da equidade, do respeito à diversidade e gestão democrática da educação. 
Ao aprofundarem os aspectos relacionados ao respeito à diversidade, em particular as questões de gênero e sexualidade, os documentos finais da Conae 2010 e da Conae 2014 abordaram de forma explícita essas questões, mas o mesmo não ocorre no Plano Nacional de Educação - PNE.

\section{O sistema municipal de ensino de Viamão}

Segundo o IBGE (2016), Viamão apresenta uma área de $1.497,02 \mathrm{~km}^{2}$ e população estimada de 251.033 habitantes em 2015. Seu sistema municipal de ensino consiste na organização legal dos elementos que se articulam para a efetiva concretização da

autonomia do município na área da educação e tem a competência de credenciar, autorizar e supervisionar as instituições de educação básica mantidas pelo Poder Público Municipal e as instituições com educação infantil criadas e mantidas pela iniciativa privada.

Pela lei municipal n. 4.365/2015, publicada em 24 de junho de 2015, foi aprovado o Plano Municipal de Ensino de Viamão 2014-2024, com vistas ao cumprimento do disposto no art. 214 da Constituição Federal e na lei n. 13.005, de 25 de junho de 2014 (Viamão, 2015).

São diretrizes do PME de Viamão a erradicação do analfabetismo; universalização do atendimento escolar; superação das desigualdades educacionais, com ênfase na promoção da cidadania e na erradicação de todas as formas de discriminação; melhoria da qualidade da educação; formação para o trabalho e para a cidadania, com ênfase nos valores morais e éticos em que se fundamenta a sociedade; promoção do princípio da gestão democrática da educação pública; promoção humanística, científica, cultural e tecnológica do País; valorização dos profissionais da educação; e promoção dos princípios do respeito aos direitos humanos, à diversidade e à sustentabilidade socioambiental (Viamão, 2015).

O PME estabeleceu várias metas a serem alcançadas, dentre as quais destacam-se incentivar a participação dos pais ou responsáveis nas atividades escolares dos filhos, mobilizando as famílias e aproximando a família da escola; implementar políticas de prevenção à evasão motivada por preconceito ou por quaisquer formas de discriminação; universalizar o acesso à educação básica para a população de quatro a dezessete anos, estendendo-a para as pessoas portadoras de necessidades especiais (Viamão, 2015).

O projeto político-pedagógico - PPP - elaborado pela Secretaria Municipal de Educação é um documento único que referencia todas as escolas da rede municipal de ensino. Seus principais fundamentos e concepções baseiam-se no entendimento de que a educação é um processo que se inicia com a família, antes de a criança ingressar na escola, e se estende ao longo da vida. Sendo assim, o PPP da rede municipal de ensino de Viamão buscou enxergar a educação como um processo integral do ser humano, considerando as dimensões sociocultural, cognitiva, afetiva, ética e histórica, entre outras, sendo muito importante conhecer o contexto familiar e a comunidade onde a escola está inserida (Viamão, 2016). 
A Rede de educação de Viamão conta com 60 escolas municipal de ensino fundamental em funcionamento, sendo 44 escolas na área urbana e 16 escolas na área rural com um total de 23.126 alunos matriculados no ano de $2015^{1}$.

No que diz respeito ao levantamento do perfil dos estudantes até o ano de 2011, a Secretaria Municipal de Educação de Viamão deixava sob responsabilidade da direção de cada escola da rede municipal definir qual o formulário a ser utilizado, acarretando uma grande variedade de formulários e falta de padronização.

No início do ano de 2011 a Secretária de Educação, em conjunto com a direção das escolas municipais, decidiu padronizar e organizar o documento para todo o município, com o objetivo de atualizar as informações coletadas, incluindo dados do número de identificação social, número da carteira do Sistema Único de Saúde, se o aluno portava deficiência locomotora ou outro tipo de deficiência, além das demais informações presentes nas fichas anteriores das escolas. Após algumas reuniões, estabeleceu-se um documento padrão para levantamento do perfil do aluno, a ser preenchido no momento da matrícula ou rematrícula, conforme descrito na figura 1.

Figura 1 -

Ficha de matrícula e rematrícula utilizada pela Secretaria Municipal de Educação de Viamão.

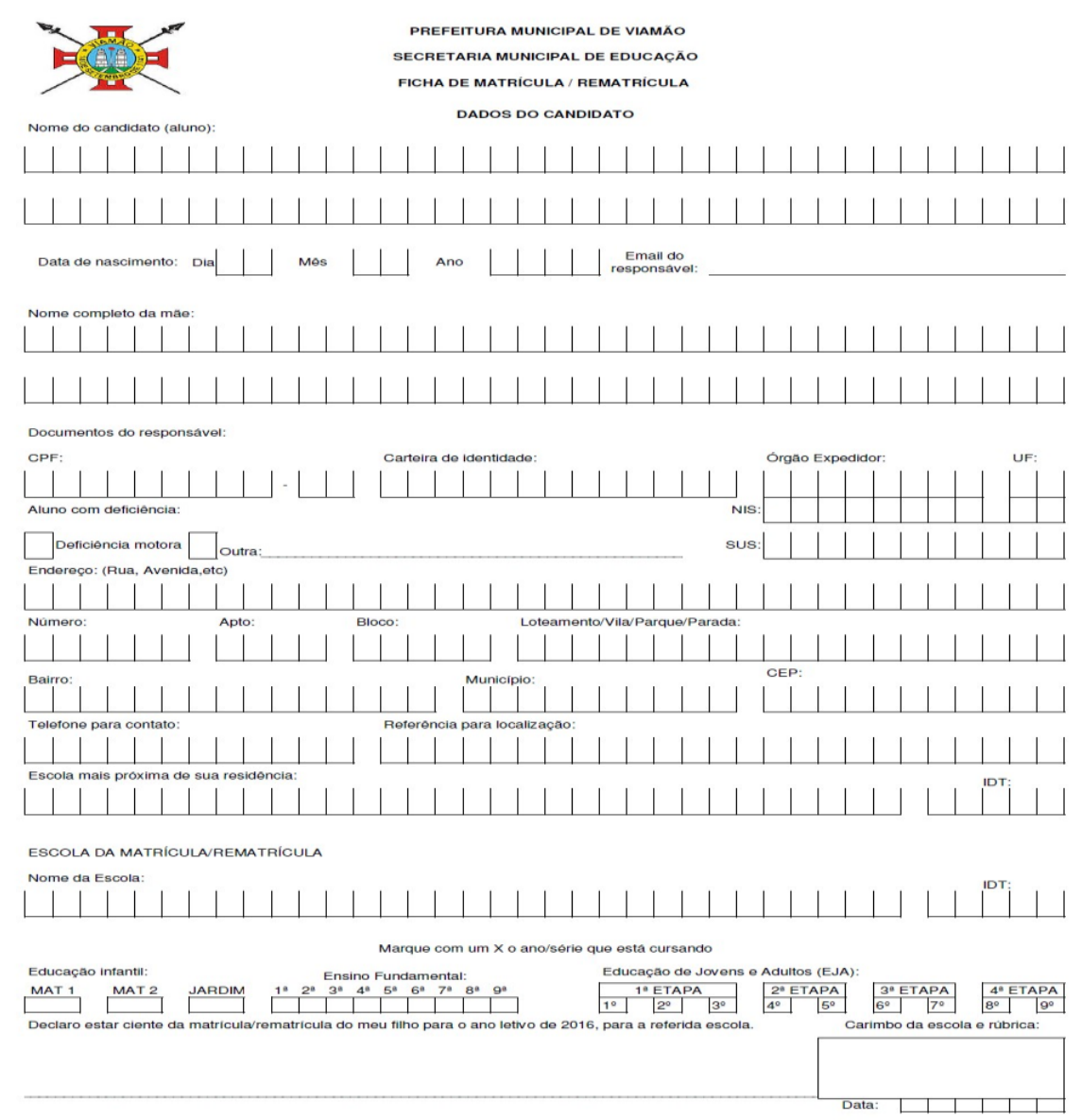

Fonte: Viamão (2015).

1 Dados coletados via entrevista com a Secretaria Municipal de Educação de Viamão. 


\section{A identificação do perfil do aluno na rede municipal de ensino de Viamão}

Buscou-se recuperar a experiência da rede municipal de ensino de Viamão no processo de levantamento do perfil do aluno, mediante a realização de entrevistas semiestruturadas com representantes da Secretaria Municipal de Educação, nos meses de maio e junho de 2016.

Pelas entrevistas percebeu-se que a Secretaria Municipal de Educação de Viamão identifica o perfil dos alunos mediante coleta rotineira de dados, com periodicidade mínima de uma vez ao ano, no período da matrícula ou rematrícula, e sempre que ocorre alguma alteração significativa. As informações são, prioritariamente, de cunho cadastral e as entrevistadas destacaram a necessidade de aprofundar os estudos com informações que possibilitem conhecer melhor a realidade do aluno e compreender a diversidade presente na sala de aula. As entrevistadas destacaram que no início do ano de 2011, a Secretária de Educação, em conjunto com a direção das escolas municipais, padronizou e organizou o documento, conforme apresentado no modelo na figura 1, no qual percebeuse um caráter cadastral. A Secretaria Municipal de Educação de Viamão permite que cada escola, identificando alguma necessidade adicional, levante outras informações em formulários específicos, para demandas pontuais. Porém, a partir da análise do formulário padrão, foi possível perceber que a discussão da rede girou em torno de dados objetivos sobre os estudantes que comporiam o formulário, e não sobre a importância de conhecer o perfil dos alunos, suas trajetórias e vivências de forma mais ampla.

Ao ser questionada sobre outros levantamentos realizados pela Secretaria Municipal de Educação de Viamão, a entrevistada declarou sentir a necessidade de uma metodologia que possibilite conhecer melhor a realidade dos alunos.

A análise das respostas das entrevistadas às perguntas formuladas pelo pesquisador possibilitou compreender como se realiza o processo de levantamento do perfil dos alunos da rede municipal de Viamão e evidencia a trajetória percorrida pela Secretaria Municipal de Educação de Viamão. Os relatos obtidos por meio das entrevistas deixam transparecer a necessidade de a rede municipal aprofundar as discussões sobre a utilização do diagnóstico da realidade dos estudantes como parâmetro de gestão educacional.

\section{A Pense e suas possibilidades}

Procurou-se destacar os dados publicados na Pense (IBGE, 2012) referentes aos recortes definidos na etapa três dos procedimentos metodológicos, com enfoque nos resultados obtidos nas escolas públicas do Brasil, recortados em função das variáveis a serem estudadas.

No Brasil 109.104 alunos responderam à pesquisa, que foi aplicada em 2.842 escolas, compostas de 4.091 turmas, com 134.310 alunos matriculados, 132.123 alunos frequentes e 110.873 alunos presentes.

Perfil dos alunos

Com relação ao sexo os resultados mostraram que $52,5 \%$ são do sexo feminino e que $47,5 \%$ são do sexo masculino. A distribuição estimada dos escolares que frequentam o 9ำ ano da escola pública, segundo cor ou raça, mostrou maiores proporções de pardos 
$(45,0 \%)$ e brancos $(33,4 \%)$. Nos demais grupos de cor ou raça, as proporções foram de $14,3 \%$ para pretos, 3,8\% para amarelos e 3,5\% para indígenas.

A estrutura etária observada entre os participantes da pesquisa no Brasil revelou que $84,2 \%$ dos escolares frequentando o $9^{\circ}$ ano do ensino fundamental da rede pública tinham de 13 a 15 anos de idade, segmento etário preconizado pela Organização Mundial da Saúde como referência para os estudos de adolescentes escolares.

Os resultados mostraram que os adolescentes frequentando o $9^{\circ}$ ano do ensino fundamental da rede pública com 16 anos ou mais, no âmbito do Brasil, se concentram entre pardos e pretos $(65,4 \%)$, seguidos por brancos $(26,3 \%)$, amarelos $(4,4 \%)$ e indígenas (3,9\%).

Nos estudos de desigualdade educacional, cor ou raça são uma variável frequente, envolvendo comparações entre diferentes grupos raciais, principalmente brancos e nãobrancos, como na tese apresentada por Brito (2014) sobre desigualdade no sistema educacional. Na mesma linha, Silva e Hasenbalg (2000) consideraram importante a presença da variável cor ou raça em estudos sobre desigualdades educacionais, em função da persistência das desigualdades para anos de estudo entre brancos e nãobrancos. A pesquisa conduzida por Riani e Rios-Neto (2008) sobre background familiar versus perfil escolar do município tornou evidente a importância da cor ou raça do indivíduo em estudos educacionais devido às desvantagens educacionais de negros em relação aos brancos.

Com relação ao tema trabalho foi observado o percentual de escolares do $9^{\circ}$ ano do Ensino Fundamental que tinham, ou não, algum trabalho, emprego ou negócio e que recebiam dinheiro, ou não, por desempenhar esta atividade. Os dados revelaram que, no Brasil, $86,9 \%$ dos escolares responderam que não trabalhavam, $11,9 \%$ responderam trabalhar e receber dinheiro, e 1,2\% respondeu trabalhar sem remuneração.

Contexto familiar do estudante

Os fatores socioeconômicos exercem papel central no desenvolvimento físico, psicológico e social das crianças e adolescentes. As condições econômicas, culturais, biológicas e ambientais nas quais os indivíduos e grupos familiares estão inseridos irão influenciar o desenvolvimento dessa comunidade. A Pense (IBGE, 2012) pesquisou alguns aspectos socioeconômicos dos escolares, de modo a obter indicadores que estabeleçam diferenciais das condições de vida do público alvo estudado, entre eles, o número de residentes no domicílio do estudante, a posse de bens e a disponibilidade do serviço doméstico no domicílio do escolar, entre outros.

A Pense (IBGE, 2012) pesquisou o total de moradores que residiam no domicílio do escolar e mostrou que $50,8 \%$ dos estudantes viviam em domicílios que tinham de três a quatro moradores e $34,1 \%$ em residências com cinco a seis moradores.

Outras variáveis pesquisadas foram questões sobre a posse de bens no domicílio de residência do aluno, tais como: existência de computador excluindo-se tablet e palm top; acesso à Internet. 
Os dados mostraram que $59,8 \%$ dos alunos das escolas públicas do Brasil declararam possuir algum tipo de computador na residência, 53,5\% possuem acesso à Internet na residência. Os indicadores resultantes deste levantamento demarcam desigualdade de acesso às tecnologias de informação e comunicação por parte dos estudantes.

Destaca-se que a Pense (IBGE, 2012) pesquisou um assunto atual relacionado ao acesso à informação. Para as instituições de ensino o conhecimento do acesso à internet e da posse de computador, tablet, laptop, etc., fora dos muros escolares possibilita saber se os estudantes têm acesso a fontes de pesquisa, de leitura e de jogos que possam auxiliá-los no processo de construção do conhecimento e aprendizagem. Além disso, conhecer a estrutura que o aluno possui em sua residência permite à escola ampliar esse assunto, a fim de conhecer quais temas os adolescentes leem, de quais jogos gostam, quais sites frequentam, enfim, tentar compreender quais atividades estimulam esses jovens, contribuindo com o processo de ensino e aprendizagem.

As mudanças socioeconômicas das últimas décadas provocaram modificações na estrutura das famílias, fazendo emergir novos arranjos familiares. Com relação a esse tema, Nunes e Vilarinho (2001) exemplificam novos arranjos familiares, tais como, mães solteiras e independentes financeiramente, avós que assumem a responsabilidade pelos netos em função da ausência dos pais por diferentes razões, tios e avós que se agregam aos núcleos familiares. No entanto, para Saraiva e Wagner (2013), não parece haver um movimento da escola no sentido de melhor compreender a realidade vivida por seus alunos e famílias.

A Pense (IBGE, 2012) revelou que 62,1\% dos escolares responderam morar em lares com a presença de pai e mãe; $28,5 \%$ informaram morar só com a mãe; $4,0 \%$ só com o pai; e 5,4\% responderam não morar nem com a mãe, nem com o pai.

\section{Ambiente educacional em casa}

A fim de analisar o ambiente educacional na casa do estudante a Pense (IBGE, 2012) mediu os indicadores de nível de instrução da mãe e do pai, conhecimento dos pais ou responsáveis sobre o tempo livre dos escolares, falta às aulas sem o consentimento dos pais ou responsáveis, verificação dos deveres de casa pelos pais ou responsáveis, entendimento dos pais ou responsáveis quanto aos problemas e preocupações dos filhos.

A instrução dos pais e sua influência no desempenho escolar dos filhos é um tema frequente em educação. Segundo Riani e Rios-Neto (2008), muitos estudos mostraram que a educação dos pais tem forte influência no resultado educacional dos filhos com ênfase na escolaridade materna.

A escolaridade da mãe merece destaque nos estudos e pode ser considerada um importante fator de proteção para a educação de crianças e adolescentes, conforme relataram Silva e Hasenbalg (2001).

A Pense (IBGE, 2012) analisou a escolaridade materna e paterna. No Brasil, 34,5\% dos escolares responderam que as mães não possuíam qualquer grau de ensino ou possuíam somente o Ensino Fundamental incompleto e 35,7\% dos pais não tinham qualquer grau de ensino ou tinham somente o Ensino Fundamental incompleto. 
Alguns estudos procuram compreender os diferentes aspectos concernentes ao relacionamento entre pais e filhos e suas consequências para a educação. Segundo Bolsoni-Silva e Marturano (2002), estabelecer limites e responsabilidades, facilitar a comunicação e a expressão de afeto podem ser considerados como essenciais à promoção da autoestima, desenvolvimento de autonomia e habilidades sociais nos filhos.

Os resultados da Pense (IBGE, 2012) demonstraram que 56,3\% dos escolares da escola pública declararam que os pais ou responsáveis sabiam o que eles faziam em seu tempo livre nos últimos 30 dias, sendo $60,3 \%$ do sexo feminino e $52,0 \%$ do sexo masculino.

Outro importante fator de proteção é o interesse dos pais na vida cotidiana dos filhos, lugares que frequentam e se faltam às aulas sem sua autorização. Com relação a esse tema, os dados da Pense (IBGE, 2012) mostraram que o percentual de escolares do 9 ํao do ensino fundamental das escolas públicas do Brasil que faltaram às aulas nos 30 dias anteriores à pesquisa sem permissão dos pais ou responsáveis foi de $28,2 \%$ no total.

Com evidente impacto na educação a Pense (IBGE, 2012) lançou algumas luzes sobre 0 envolvimento entre pais e filhos com relação aos deveres de casa. $O$ acompanhamento dos deveres de casa é visto como uma forma positiva de filhos e pais interagirem e de estes acompanharem o desenvolvimento dos filhos na escola (Ramires, 2004).

O hábito dos pais ou responsáveis de verificar se foram feitos os deveres de casa dos escolares foi investigado na Pense (IBGE, 2012): 33,4\% dos escolares responderam que seus pais ou responsáveis acompanharam seus deveres de casa.

A Pense (IBGE, 2012) também verificou com que frequência, nos últimos 30 dias, os pais ou responsáveis entenderam os problemas e preocupações dos filhos. Dos escolares pesquisados nas escolas públicas do Brasil, $45,5 \%$ responderam que os pais ou responsáveis se interessavam por seus problemas e preocupações.

Ambiente educacional na escola

Com relação ao ambiente educacional na escola, destaca-se que o bullying tem se difundido entre crianças e adolescentes, instalando-se principalmente no contexto escolar. Atinge, principalmente, crianças e adolescentes que não se encaixam nos padrões valorizados por uma determinada pessoa ou grupo. Devido à relevância desse assunto no ambiente escolar, essa variável foi pesquisada na Pense (IBGE, 2012).

Dados da Pesquisa de Comportamento de Saúde em Crianças em Idade Escolar da Organização Mundial da Saúde para países da Europa e América do Norte mostraram que $13,0 \%$ dos alunos com 11 anos de idade sofreram bullying na escola por, no mínimo, duas vezes nos dois meses anteriores à pesquisa (Currie et al., 2012). Estudos realizados em 50 estados e no Distrito de Columbia, nos Estados Unidos, com 15.503 estudantes de 158 escolas, revelaram que $20,1 \%$ dos estudantes foram vítimas de bullying na escola nos 12 meses que antecederam a pesquisa. (Eaton et al., 2012).

Os resultados da Pense (IBGE, 2012) mostraram que $54,7 \%$ dos estudantes do 9 ano do ensino fundamental da escola pública no Brasil foram bem tratados pelos colegas quase sempre ou sempre. A análise dos resultados por sexo indicou que, para o Brasil, $60,4 \%$ das alunas declararam ter sido bem tratadas pelos colegas, enquanto que entre os meninos esse percentual foi de $48,5 \%$.

Regae: Rev. Gest. Aval. Educ. Santa Maria v. 6

ก. 12

Maio/ago., 2017 p. $107-123$ 
Em relação ao fato de sofrer bullying pelos colegas de escola $7,1 \%$ dos escolares afirmaram que sempre ou quase sempre se sentiram humilhados por provocações, sendo que os percentuais foram maiores entre os estudantes do sexo masculino $(7,8 \%)$ do que do feminino $(6,4 \%)$.

Os resultados da Pense (IBGE, 2012) demonstraram que, na escola pública do Brasil, 20,3\% dos estudantes praticaram algum tipo de bullying - esculachar, zoar, mangar, intimidar ou caçoar - contra os colegas, levando-os a se sentirem magoados, incomodados ou aborrecidos; nos últimos 30 dias anteriores à pesquisa.

\section{Conclusão}

Os documentos levantados junto à Prefeitura Municipal de Viamão, as entrevistas realizadas, os achados bibliográficos e as tendências apontadas pela Pense (IBGE, 2012) indicaram caminhos e possibilidades para reflexão e ação sobre as variáveis a serem propostas, a fim de ampliar o escopo atual empregado na Secretaria Municipal de Educação de Viamão para utilização do perfil dos estudantes como parâmetro de gestão educacional.

O estudo desse material apontou para as complementações necessárias ao instrumento básico hoje utilizado para levantar o perfil do aluno na rede municipal de ensino de Viamão. Com a inclusão de novas variáveis espera-se individualizar os alunos que adentram a sala de aula, melhor compreendendo suas particularidades no fazer docente, contribuindo com o processo de ensino e aprendizagem.

No quadro 1 se apresenta o parâmetro do cadastro do aluno que se encontra embasado nos três pilares propostos neste trabalho.

Quadro 1 -

Parâmetro do cadastro do aluno.

\begin{tabular}{|c|c|c|c|}
\hline \multicolumn{4}{|l|}{ I - Dados de identificação } \\
\hline \multicolumn{4}{|l|}{ Nome completo: } \\
\hline \multicolumn{2}{|l|}{ Local de nascimento: } & \multicolumn{2}{|c|}{ Data de nascimento: } \\
\hline \multicolumn{2}{|l|}{ Nacionalidade: } & \multirow{2}{*}{\multicolumn{2}{|c|}{ Identidade de gênero: }} \\
\hline \multicolumn{2}{|l|}{ Sexo: ( ) Masculino ( ) Feminino } & & \\
\hline \multicolumn{4}{|c|}{ Cor/Raça: ( ) Amarela ( ) Branca ( ) Indígena } \\
\hline \multicolumn{4}{|c|}{ Endereço residencial: } \\
\hline Telefone residencial: & \multicolumn{2}{|l|}{ Celular (pai): } & Celular (mãe): \\
\hline \multicolumn{4}{|l|}{ Nome da mãe: } \\
\hline \multicolumn{2}{|l|}{ Escolaridade da mãe: } & \multicolumn{2}{|c|}{ Profissão da mãe: } \\
\hline \multicolumn{4}{|l|}{ Nome do pai: } \\
\hline \multicolumn{2}{|l|}{ Escolaridade do pai: } & \multicolumn{2}{|c|}{ Profissão do pai: } \\
\hline \multicolumn{4}{|l|}{ II - Contexto familiar do aluno } \\
\hline \multicolumn{4}{|l|}{ Com quem vive o(a) aluno(a): } \\
\hline $\begin{array}{ll}\text { ( ) Ambos os pais } & \text { ( ) Com a mãe } \\
\text { ( ) Pais adotivos } & \text { ( ) Com irmãos }\end{array}$ & $\begin{array}{l}\text { ( ) Com o pai } \\
\text { ( ) Outro: }\end{array}$ & ( ) Com os avós & ( ) Com o(a) tutor(a) \\
\hline \multicolumn{4}{|l|}{ Nome do responsável pelo aluno: } \\
\hline \multicolumn{4}{|l|}{ Endereço do responsável pelo aluno: } \\
\hline Documentos do responsável pelo aluno: & & & \\
\hline
\end{tabular}




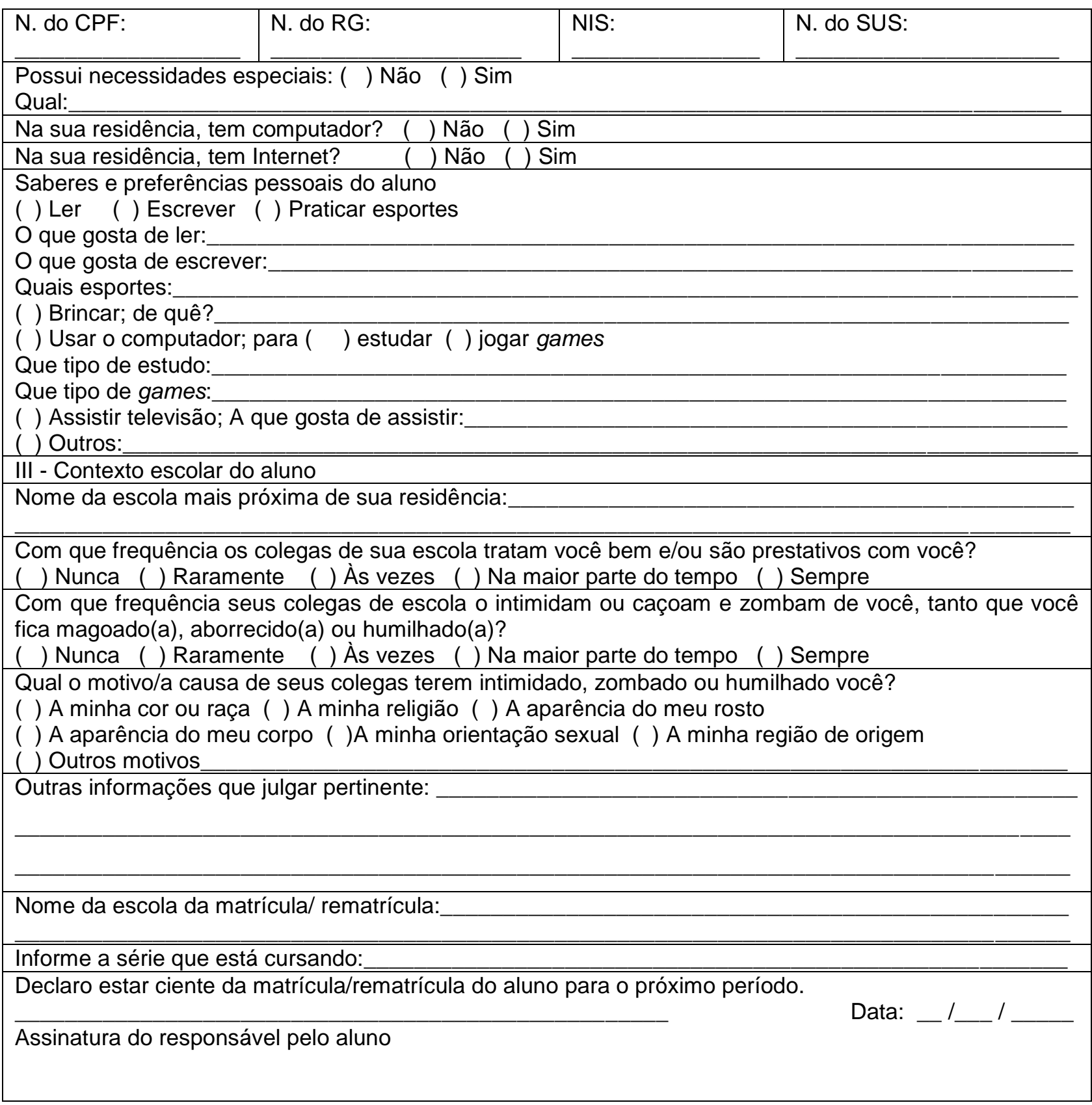

Fonte: Elaborado pelos autores.

Importante ressaltar que o parâmetro proposto deve ser constantemente reavaliado e atualizado com base em novos estudos e pesquisas que tragam informações sobre a área em questão. Os gestores educacionais devem estar atentos para as modificações ocorridas na sociedade, bem como para as novas demandas surgidas na escola.

\section{Referências}

ARIÈS, Philippe. História social da criança e da família. Rio de Janeiro: Guanabara, 1981. BOLSONI-SILVA, Alessandra Turini; MARTURANO, Edna Maria. Práticas educativas e problemas de comportamento: uma análise a luz das habilidades sociais. Estudos de Psicologia, Campinas, v. 7, n. 2, 2002, p. 227-235. 
BRASIL. Lei n. 13.005, de 25 de junho de 2014. Aprova o Plano Nacional de Educação PNE e dá outras providências. Disponível em <http://www.planalto.gov.br/ccivil_03/_ato2011-2014/2014/lei//13005.htm>. Acesso em 12 mar. 2016.

BRITO, Murillo Marschner Alves de. A dependência na origem: desigualdades no sistema educacional brasileiro e a estruturação social das oportunidades. São Paulo: USP, 2014. 270f. Tese (doutorado em Sociologia). Programa de Pós-Graduação em Sociologia, Universidade de São Paulo.

CHAVES, Miriam Waidenfeld. As relações entre a escola e o aluno: uma história em transformação. Revista Educação e Realidade, Porto Alegre, v. 40, n. 4, 2015, p. 11491167.

CONFERÊNCIA NACIONAL DE EDUCAÇÃO - CONAE. Documento final da Conferência Nacional de Educação 2010: construindo o sistema nacional articulado de educação: o plano nacional de educação, diretrizes e estratégias de ação. Brasília: MEC, 2010. Disponível em http://conae.mec.gov.br/images/stories/pdf/pdf/documetos/documento_final.pdf>. Acesso em 12 abr. 2016.

CONFERÊNCIA NACIONAL DE EDUCAÇÃO - CONAE. Documento final da Conferência Nacional de Educação 2014: O PNE na Articulação do Sistema Nacional de Educação. Brasília: MEC, $2014 . \quad$ Disponível em: http://fne.mec.gov.br/images/doc/DocumentoFina240415.pdf>. Acesso em: 17 abr. 2016.

CURRIE, Candace et al (ed.). Social determinants of health and well-being among young people: Health Behaviour in School-Aged Children (HBSC) study: international report from the 2009/2010 survey. Copenhagen: World Health Organization - WHO; Edinburg: University of Edinburgh, Child and Adolescent Health Research Unit - CAHRU, 2012.252 p. (Health policy for children and adolescents, $n$. 6). Disponível em <http://www.euro.who.int/_data/assets/pdf_file/0003/163857/Social-determinants-ofhealth-andwell-being-among-young-people.pdf>. Acesso em 10 set. 2015.

EATON, Danice et al. Youth risk behavior surveillance, United States, 2011. Morbity and Mortality Weekly Report. Atlanta: Centers for Disease Control and Prevention - CDC, v. 61, n. 4, 2012, p. 1-162, Jun. 2012. Disponível em <http://www.cdc.gov/mmwr/pdf/ss/ss6104.pdf>. Acesso em 16 mar. 2016.

FÁVERO, Antonio Sobrinho. O aluno não é mais aquele! $E$ agora, professor? A transfiguração histórica dos sujeitos da educação. SEMINÁRIO NACIONAL CURRÍCULO EM MOVIMENTO - PERSPECTIVAS ATUAIS, 1, 2010, Belo Horizonte. Anais ... Belo Horizonte: Ministério da Educação, 2010, p. 1-18. Disponível em <http://portal.mec.gov.br/docman/dezembro-2010-pdf/7176-4-1-aluno-nao-e-mais-aqueleantonio-favero/file>. Acesso em 17 nov. 2015.

INSTITUTO BRASILEIRO DE GEOGRAFIA E ESTATÍSTICA. IBGE: cidades@: Viamão: RS. Rio de Janeiro, 2016.2 Disponível em: $<$ http://www.cidades.ibge.gov.br/xtras/perfil.php?lang=\&codmun=432300\&search=riogrande-do-sul|viamao>. Acesso em: 16 jan. 2016.

INSTITUTO BRASILEIRO DE GEOGRAFIA E ESTATÍ́STICA . Pense: pesquisa nacional de saúde do escolar 2012. Rio de Janeiro, 2012. Disponível em <http://www.ibge.gov.br/home/estatistica/populacao/pense/2012/>. Acesso em 5 nov. 2015. 
KLEIN, Remi. Questões de gênero e sexualidade nos planos de educação. Coisas do gênero: Revista de Estudos Feministas em Teologia e Religião, São Leopoldo, v. 1, n. 2, 2015, p. 145-156.

LOPES, Maura Corcini. In/exclusão escolar: a invenção de tipos específicos de alunos. Revista Colombiana de Educación, Bogotá, n. 54, 2008, p. 96-119.

NUNES, Dulce Gomes; VILARINHO, Lúcia Regina Goulart. Família possível na relação escola-comunidade. Psicologia Escolar e Educacional, Uberlândia, v. 5, n. 2, 2001, p. 2129.

UNESCO. Primera reunión intergubernamental del proyecto regional de educación para América Latina y el Caribe, La Habana, Cuba, 14-16 de noviembre, 2002: informe final. La Habana, 2002. Disponível em: <http://portal.unesco.org/geography/es/ev.phpURL_ID=8521\&URL_DO=DO_TOPIC\&URL_SECTION=201.html>. Acesso em 12 nov. 2015.

POLONIA, Ana da Costa; DESSEN, Maria Auxiliadora. Em busca de uma compreensão das relações entre família e escola. Psicologia Escolar e Educacional, Maringá, v. 9, n. 2, 2005, p. 303-312.

RAMIRES, Vera Regina Röhnelt. As transições familiares: a perspectiva de crianças e pré-adolescentes. Psicologia em Estudo, Maringá, v. 9, n. 2, 2004, p. 183-193.

RIANI, Juliana de Lucena Ruas; RIOS-NETO, Eduardo Luiz Gonçalves. Background familiar versus perfil escolar do município: qual possui maior impacto no resultado educacional dos alunos brasileiros? Revista Brasileira de Estudos de População, São Paulo, v. 25, n. 2, 2008, p. 251-269.

SANTOS, Maria de Fátima Souza; CRUZ, Fátima Maria Leite; BELÉM, Rosemberg. Adolescentes podem ser alunos ideais? Educação em Revista, Belo Horizonte, v. 30, n. 3, 2014, p. 173-193.

SARAIVA, Lisiane Alvim; WAGNER, Adriana. A relação família-escola sob a ótica de professores e pais de crianças que frequentam o ensino fundamental. Ensaio: avaliação $e$ políticas públicas em educação, Rio de Janeiro, v. 21, n. 81, 2013, p. 739-772.

SILVA, Nelson do Valle; HASENBALG, Carlos. Tendências da desigualdade educacional no Brasil. Dados - Revista de Ciências Sociais, Rio de Janeiro, v. 43, n. 3, 2001, p. 423445.

VARELA, Julia; ALVAREZ-URIA, Fernando. La maquinaria escolar. In: ALVAREZ-URIA, Fernando; VARELA, Julia. Arqueología de la escuela. Madrid: La Piqueta, 1991, p. 13-54.

VIAMÃO (Município). Lei municipal n. 4.365, de 24 de junho de 2015. Aprovado o Plano Municipal de Educação de Viamão 2014-2024. Prefeitura Municipal, Viamão. 2015. Documento em pdf.

VIAMÃO. Prefeitura Municipal. Projeto político-pedagógico. Viamão, 2016b.

XAVIER, Maria Luisa Merino. Os incluídos na escola: o disciplinamento nos processos emancipatórios. Porto Alegre: Ufrgs, 2003. 264f. Tese (doutorado em Educação). Programa de Pós-Graduação em Educação, Universidade Federal do Rio Grande do Sul. 
Decio Tadeu Dalcin Pigato é professor no Instituto Federal do Rio Grande do Sul, campus de Erechim, mestre em Gestão Educacional pela Universidade do Vale do Rio dos Sinos.

Endereço: Rua Domingos Zanella, 104 - 99713-028 - Erechim - RS - Brasil.

E-mail: decio.pigato@erechim.ifrs.edu.br.

Silvana Maria Paes Cangiani é tecnologista no Instituto Brasileiro de Geografia e Estatística, doutora em Ciências Biológicas pela Universidade Estadual Paulista de Botucatu.

Endereço: Av. Augusto de Carvalho, 1205 - 90010-390 - Porto Alegre - RS - Brasil. E-mail: smcangiani@gmail.com.

Recebido em 18 de fevereiro de 2017.

Aceito em 21 de junho de 2017. 